Int. J. Dev. Biol. 52: 115-119 (2008)

doi: $10.1387 / \mathrm{ijdb} .072382 \mathrm{mk}$

\title{
Basic Science B.D. (before Drosophila): Cytology at the University of Warsaw (Poland)
}

\author{
MALGORZATA KLOC* \\ Department of Biochemistry and Molecular Biology, The University of Texas, M. D. Anderson Cancer Center, Houston, Texas, USA
}

\begin{abstract}
The majority of modern research in cell and developmental biology is based almost exclusively on seven model organisms: mouse, zebra fish, Xenopus laevis frog, Drosophila fly, Caenorabditis elegans worm, Arabidopsis plant and yeast. Although the validity and practicality of these model systems and their impact on scientific progress are undeniable, the combination of goal-oriented science and the use of the model systems introduces, a priori, a dangerous limitation to scientific discovery. Consequently, many astonishing phenomena occurring in nonmodel organisms are either never studied or, disappear from scientific consciousness. A perfect example is the fate of the important studies by Professor Zygmunt Kraczkiewicz on chromatin diminution in Cecidomyiidae (Diptera) conducted before World War II and continued by his team until early 1990 in the Department of Cytology at Warsaw University in Poland. These light and electron microscopy studies have not been elevated to the molecular level, and although they deserve to be extensively studied and cited by researchers working in the field of soma and germ cell differentiation and specification, they have been, within the past $\mathbf{4 0}$ years, nearly completely wiped out of scientific memory. This article presents a short summary of this important research in the historical context of pre- and post-war science at Warsaw University in Poland.
\end{abstract}

KEY WORDS: Cecidomyiidae, Diptera, germ cell, germ plasm, chromosome elimination

In the contemporary world of biological sciences with the pressure of increasingly limited funding for research, the real Basic Science, i.e., a research that is aimed not at solving specific problems but one that provides knowledge just for the sake of knowing and for the intellectual endeavor of satisfying the curiosity, is being slowly ousted and replaced by semi-basic science with the immediate goal of application for the improvement of human life. In addition, the vast majority of the modern research in cell and developmental biology is based almost exclusively on seven model organisms: mouse, zebra fish, Xenopus laevis frog, Drosophila fly, Caenorabditis elegans worm, Arabidopsis plant and yeast. The validity and practicality of the model systems and their impact on scientific progress are undeniable. The great number of phenomena and mechanisms discovered in the model organisms are obviously universal and applicable to any living entity. However, the combination of goal-oriented science and the use of the model systems (plus the very natural human weakness of scientists of wanting to be trendy) introduces, a priori, a dangerous limitation to scientific discovery. In reality, even the important discoveries that involve the organisms outside of the model systems or do not belong to trendy topics are perceived as being inapplicable and are very often unfundable and unpublishable in the mainstream journals. Consequently, many astonishing phenomena occurring in the non-model organisms are either never studied or, if studied, after being published in low-impact journals, disappear from scientific consciousness which is a great loss for science, and often resulting in the new generation of scientists' having to reinvent the wheel.

The perfect example of such a loss is the fate of the important studies by Professor Zygmunt Kraczkiewicz (Figs. 1, 2) on the chromatin diminution in Cecidomyiidae (Diptera) conducted before World War II and continued by his team until early 1990 in the Department of Cytology at Warsaw University in Poland. These light and electron microscopy studies, have not been elevated to the molecular level, and although they deserve to be extensively studied and cited by researchers working in the field of soma and germ cell differentiation and specification, they have been, within the past 40 years, with the Drosophila model slowly creeping in, nearly completely wiped out of scientific memory.

In December 1945, seven months after the end of World War II, Warsaw University inaugurated it's re-opening. One of the resurrected faculties was that of Mathematics and Earth Science,

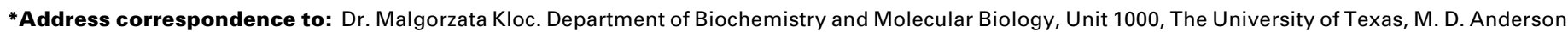
Cancer Center, 1515 Holcombe Blvd., Houston TX 77030, USA. Tel: +1-713-828-4112. Fax: +1-713-792-0346. e-mail: mkloc@mdanderson.org
}

Published online: 14 February 2008 
which during the war lost not only its buildings and all infrastructure but, most importantly, a crucial part of its scientific cadre: 12 professors of biology lost their lives. Fortunate to survive was Professor Zygmunt Kraczkiewicz, my first scientific mentor, whose fascinating lectures and cytology courses showing spider and diplopod oocytes with mysterious organelle called yolk nucleus (Balbiani body) (for recent reviews see De Smedt et al., 2000 and Kloc et al., 2004) steered my ubiquitous love of biology toward cell biology and the enchantments of oogenesis.

Prof. Kraczkiewicz was born on July 20, 1900 in Biala in Ukraine. He graduated from Naumenko gymnasium in Kiev in 1919. In 1922 after completing, as a second lieutenant, two years of service in the Military School of Automobile Force, he enrolled in the Faculty of Philosophy at Warsaw University. In 1928 he received his Ph.D., and in 1935 the doctor habilitatus (D.Sc.) degree. From 1926 until 1939 he was an assistant professor in the Department of Cytology at Warsaw University.

With the eruption of World War II, in September 1939, he was called, in the rank of lieutenant, to active military duty. After the fall of Poland to overwhelming forces of German and Russian invaders, his armored regiment was ordered to cross the border to Romania where he was interned until 1941 (readers interested in the history of pre-war and war Poland should read the beautiful book Bitter Glory, by Richard M. Watt). In February 1941, together with other interned Polish officers, Kraczkiewicz was handed over to the Germans, and until the end of the war held captive in German POW camps, first in Dorsten and then in Dossel in Westphalia.

In 1945 after the liberation by American forces he was transferred to Belgium where he co-organized and lectured in the Polish Center of Academic Studies in Brussels. In 1946 he returned to Poland, where he accepted the position of associate professor in the newly re-opened Department of Zoological Cytology at Warsaw University and subsequently served as the Chair of the Department of Cytology from 1955 until his retirement in 1970. (He passed away in 1971). Between 1951 and 1956 he also held the position of the Dean of Faculty of Biology and Natural Sciences, and between 1956 and 1965 served as the Pro-Rector of Warsaw University.

In the early years of his scientific career Kraczkiewicz studied the phenomenon of platyneuria in bird embryos, which was also the subject of his doctoral thesis, completed under the supervision of professor Jan Tur, and several publications. Later his main scientific interests shifted toward cell biology, particularly the structure of Golgi apparatus, yolk nucleus (Balbiani body) in oocytes of diplopods, and finally the mecha-

Fig. 1. Laboratory of the Department of Cytology with members of the staff and students (1958). From the left: Ewa Perkowska (volunteer), Bohdan Matuszewski (later professor and head of the Department), professor Zygmunt Kraczkiewicz, students Teresa Pawelczyk and Grazyna Ejsmont, Janina Saska (from the Department of Physiology) and Irena Geyer-Duszynska. nisms of divisions in somatic and germline cells of gall midges (Cecidomyiidae). His pioneering studies, initiated under the supervision of professor Waclaw Baehr, and brutally interrupted by the war, of chromosome elimination and diminution in Miastor metraloas (Kraczkiewicz, 1935, 1938; for more references see Matuszewski, 1982), had been met with great interest by the scientific community. Professor Waclaw Brunon baron von Baehr was another impressive scientist and cosmopolitan associated with the department of Cytology at Warsaw University. He was born in 1873 in Makowlany, Poland, and studied biological sciences at University of Odessa and Petersburg. In early years of his scientific career he worked in German, Belgium and French scientific centers. After his return to Poland, from 1925 to1937, he held a faculty position at the Department of Cytology at Warsaw University where he worked on various aspects of oogenesis and heredity.

After the war, together with his research team of superb scientists including Bohdan Matuszewski, Irena Geyer-Duszynska, and Bozenna Jazdowska-Zagrodzinska, professor Kraczkiewicz expanded his research topics to include studies of the structure of giant salivary gland chromosomes (Kraczkiewicz and Matuszewski, 1958), chromosome segregation in oogenesis and spermatogenesis, and chromosome elimination in other species of Cecidomyiidae (for references see Matuszewski, 1982, Jazdowska-Zagrodzinska et al., 1992; Kloc and Zagrodzinska, 2001).

The Cecidomyiidae, which belong to the lower Diptera, appeared in the Cretaceous period (146-65 million years ago) of the Mesozoic era. Besides the predatory and parasitic species, Cecidomyiidae include species that develop in plant tissues and produce galls; hence, they were called gall midges. Some species of gall midges, including the above-mentioned Miastor metraloas reproduce by viviparous larvae, the process discovered by Wagner in 1862 (Matuszewski, 1982) and named paedogenesis by Baer in 1866 (Matuszewski, 1982). In Cecidomyiidae, as in other Diptera including Drosophila, the differentiation between the soma and the germ cells, called the pole cells, occurs in early

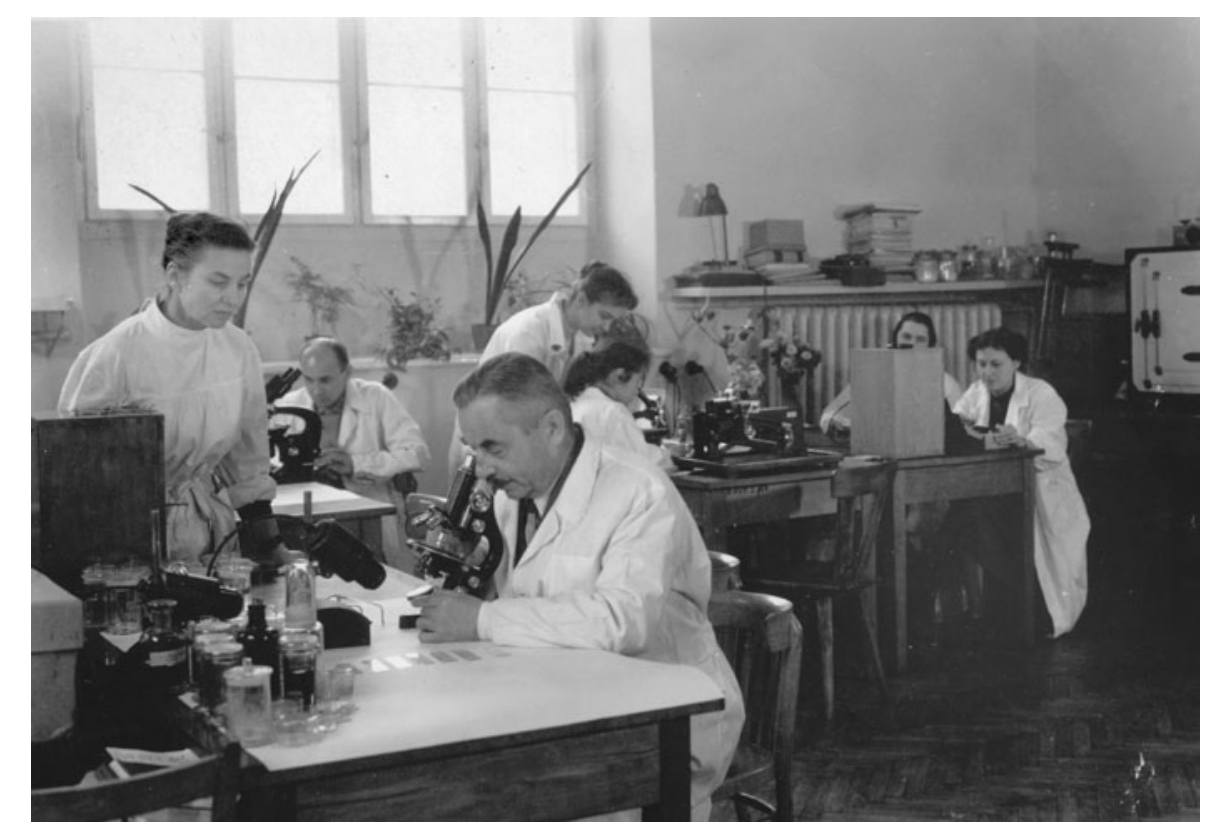


cleavage when the germ cells form at the posterior pole of the syncytial embryo. The cytoplasm of the posterior pole, also called polar plasm, germ plasm or oosome contains polar granules (germinal granules), and various localized RNAs and proteins believed to be responsible for the determination of the germ cell fate (Kloc et al., 2002; Zhou and King, 2004). However, in Cecidomyiidae, unlike in Drosophila, just after (or in some species during) the formation of the pole cells, the nuclei of presumptive somatic cells eliminate the majority of their chromosomes ( $E$ chromosomes).

This process, which may be seen as a genetic engineering in nature, is called chromosome elimination or chromatin diminution. Elimination occurs during the mitotic divisions of presumptive somatic nuclei and is accompanied by the inhibition of the movement of the eliminated chromosomes in anaphase (Matuszewski, 1982). As a result, all cells of soma will have limited number of chromosomes (S chromosomes), and only germ cells retain a whole complement of chromosomes ( $\mathrm{S}$ and $\mathrm{E})$. It is very probable that the contact of the germ cell nuclei with the polar plasm protects their chromosomes from elimination. Thus, only the nuclei outside of the polar plasm region undergo chromosome elimination.

Dr. Irena Geyer-Duszynska from the Department of Cytology at Warsaw University, initiated in 1950-ties the experimental studies on the role of the germ plasm in chromosome elimination. Her pioneering studies which involved uv radiation, mechanical constriction, and centrifugation of eggs of various species of Cecidomyiidae showed that the oosome located in the polar plasm actively inhibits chromosome elimination. In embryos in which oosome material has been experimentally removed, all nuclei underwent the elimination process. In contrast, if the oosome material was misplaced, by centrifugation, to the center of the egg, during subsequent cleavage all nuclei, which contacted misplaced oosome retained the whole complement of chromosomes (Geyer-Duszynska, 1959, 1961, 1966).

Detailed analyse of somatic nuclei in Cecidomyiidae showed a gradient of chromosome elimination along the long axis of the cleaving embryo (see references in Matuszewski, 1982). The nuclei nearest to the polar plasm have the lowest number of eliminated chromosomes and the nuclei at the anterior pole have the highest number of eliminated chromosomes (Matuszewski, 1982). This would indicate the presence in the polar plasm of diffusible factor which concentration decreases with the growing distance from its source. However, because the Drosophila somatic nuclei, which are also located outside of the polar plasm, do not undergo chromosome elimination, it follows that in Cecidomyiidae there must be some additional mechanisms or factors that promote chromosome elimination outside of the polar plasm. Another less likely possibility is that in Drosophila all the cytoplasm of the early embryo contains anti-elimination factors.

Besides the fascinating and so far unanswered issue- What are the mechanisms and molecules promoting elimination or protecting chromosomes from being eliminated? There is another unanswered question- What are the genetic and molecular differences between the $S$ and $E$ set of chromosomes? One of the most sound hypotheses is that the E chromosomes are the polyploidal representation of the $S$ chromosomes and thus that the germ line in Cecidomyiidae is polyploidal (Matuszewski, 1982). Although Kunz and Eckhardt (1974), using in situ hybridization, showed that a

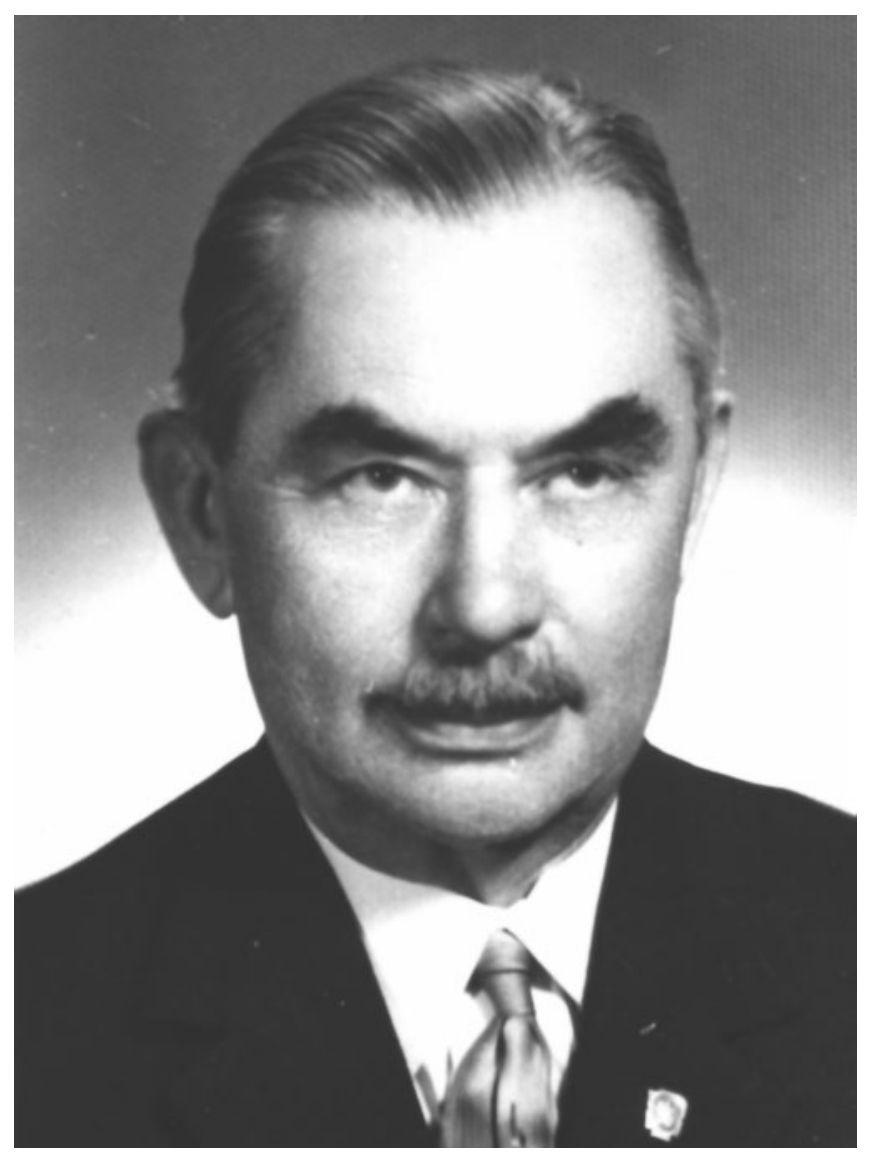

Fig. 2. Professor Zygmunt Kraczkiewicz (1965) pioneered the studies of chromosome elimination and diminution during germ cell/soma differentiation in Diptera.

fraction of repetitive DNA was present in both S and $E$ chromosomes, which supports the polyploidization hypothesis, there were no further molecular studies on this fascinating subject.

The intriguing phenomenon of whole or partial chromosome elimination represents a case of a developmentally programmed DNA rearrangement that occurs in many invertebrate and vertebrate species (for review see Kloc and Zagrodzinska, 2001). Besides chromosome elimination in Cecidomyiidae, other known and better-studied examples include chromatin diminution in ciliates, parasitic nematodes and copepods. In ciliates such as Stylonychia, Oxytricha and Euplotes, 95-98\% of the DNA sequences present in a germline nucleus (micronucleus) are lost during the maturation of a somatic nucleus (macronucleus) (Prescott 2000). In copepod Cyclops kolensi during the fourth cleavage $94 \%$ of DNA is eliminated (eDNA) from seven presumptive somatic cells and only one cell, which is the germline progenitor retains a full genome. Recently, Degtyarev et al. (2004) cloned and sequenced fraction of a Cyclops kolensieDNA and found that it was composed of a repetitive DNA containing direct and inverted repeats with a complex internal structure and spacer elements. The very complex and obviously nonrandom organization of eDNA that was retained in the germ cells suggests that rather than being junk DNA, eDNA plays some important function necessary for the germ line (Degtyarev et al., 2004).

Most of the known cases of chromatin diminution in nematodes 
occur in the parasitic family of Ascarididae (Muller and Tobler, 2000). Like in copepods and Cecidomyiidae chromatin in Ascarididae is eliminated during early embryogenesis from the presumptive somatic cells while germ line cells maintain full chromatin content, and depending on the species, $25-90 \%$ of chromatin is eliminated from the pre-somatic cells. The chromatin diminution in nematodes involves extremely complex events, which include chromosomal breakage, healing, and de novo formation of telomeres (Magnenat et al., 1999; Muller and Tobler, 2000; Bachmann-Waldmann et al., 2004). A recent study showed that the eliminated DNA contains repetitive sequences and also, at least in Ascaris suum three different single copy genes (Muller and Tobler, 2000).

In 1970/71 Prof. Bohdan Matuszewski succeeded Prof. Kraczkiewicz as the Head of the Department of Cytology at Warsaw University. Besides the continuation of the Cecidomyiidae studies (Matuszewski, 1982), he ventured into completely novel and exciting project to study the oogenesis and origin of the oocyte in insect telotrophic-meroistic ovaries. Although, at that point of time, the origin of the oocyte and nurse cells in the polytrophic-meroistic ovaries of the model insect Drosophila, was already identified and studied extensively (reviewed in King and Buning, 1985), nothing was known about the mechanisms of germ/nurse cells specification and oocyte formation in other types of insect ovaries. Matuszewski and his research group studied the developing ovary of Coleoptera-Polyphaga and discovered that, in telotrophic ovaries, the differentiation of the oocyte and nurse cells occurs, not like in Drosophila in the cysts, but within the linear clusters (chains) of sister oogonial cells connected by the intercellular bridges, which contain fusome (Matuszewski et al., 1985). They also found that in each chain of oogonial cells, only the most posterior cell (an equivalent of cystoblast in Drosophila ), which contacts the somatic tissue, becomes the pro-oocyte and eventually the oocyte, and all other cells of the chain become the nurse cells (Kloc and Matuszewski, 1977, Matuszewski et al., $1985,1999)$. In addition, they found that in telotrophic ovary of Creophilus maxillosus pro-oocyte and oocyte nuclei contain large extrachromosomal DNA body, which contains amplified copies of ribosomal DNA (rDNA) (Kloc and Matuszewski, 1977; Kloc, 1980; Matuszewski etal., 1985, 1999; Kloc etal., 1995)- this was the first ever description of rDNA amplification in polytrophic ovary. Further studies showed that in Creophilus, during consecutive oogonial divisons occurring within the chain of interconnected oogonia, the extrachromosomal rDNA always segregates preferentially to the pro-oocyte of the next generation and eventually to the oocyte (Kloc and Matuszewski, 1977). This poses (unfortunately still unanswered) question what is the role of somatic cells, and the molecular nature of emanating from them signals, in the determination of the oocyte versus nurse cell fate in the telotrophic ovary.

These are just some examples of the multitude of fascinating and very poorly understood phenomena that deserve to be studied by mainstream science, and when explained, will immensely broaden our understanding of the function of cells and developing organisms and enlighten us about the Laws of Nature.

\section{Acknowledgements}

Idedicate this article to the memory of Professor Zygmunt Kraczkiewicz and to all past, present, and future biologists who have the desire and courage to work outside of the model systems. I also want to express my immense gratitude to my scientific and intellectual mentor Professor
Bohdan Matuszewski who succeeded Professor Kraczkiewicz as the Head of the Department of Cytology at Warsaw University, for teaching me how to be a basic scientist. I also thank Dr. Anna Kraczkiewicz-Dowjat for sharing with me the hand-written autobiography of her father and Dr Teresa Rogulska for the information about prof. Baehr.

\section{References}

BACHMANN-WALDMANN, C., JENTSCH, S., TOBLER, H., MULLER, F. (2004). Chromatin diminution leads to rapid evolutionary changes in the organization of the germ line genomes of the parasitic nematodes $A$. suum and $P$. univalens. Mol Biochem Parasitol. 134:53-64.

DEGTYAREV, S., BOYKOVA, T., GRISHANIN, A., BELYAKIN, S., RUBTSOV, N., KARAMYSHEVA, T., MAKAREVICH, G., AKIFYEV. A., ZHIMULEV, I. (2004). The molecular structure of the DNA fragments eliminated during chromatin diminution in Cyclops kolensis. Genome Res. 14:2287-2294.

DE SMEDT, V., DANIEL SZOLLOSI, D., KLOC, M. (2000). The Balbiani body: Asymmetry in the mammalian oocyte Genesis, 26: $208-212$.

GEYER- DUSZYNSKA, I. (1959). Experimental research on chromosome elimination in Cecidomyiidae (Diptera). J. Exp. Zool. 141, 391-447.

GEYER- DUSZYNSKA, I. (1961). Spindle disappearance and chromosome behavior after partial embryo irradiation in Cecidomyiidae (Diptera). Chromosoma (Berl) 12, 233-247

GEYER- DUSZYNSKA, I. (1966). Genetic factors in oogenesis and spermatogenesis in Cecidomyiidae. Chromosomes Today 1, 147-178.

JAZDOWSKA-ZAGRODZINSKA, B., DALLAI, R., REDI, C. A. (1992). Changes in DNA content and chromosome number during spermatogenesis in the gall midge Monathropalpus buxi (cecidomiidae, Diptera). Genome 35: 244-250.

KING, R. C. AND BUNING, J. (1985). The origin and functioning of insect oocytes and nurse cells. In Comprehensive insect physiology, biochemistry and pharmacology. Vol 1. Kerkut G, A., Gilbert, L. I. (eds) Pergamon Press, Oxford, pp 37-82.

KLOC, M. (1980). Extrachromosomal DNA and its activity in RNA synthesis in oogonia and oocytes in the pupal ovary of Creophilus maxillosus (Staphylinidae, Coleoptera-Polyphaga) Eur. J. Cell Biol. 21, 328-334.

KLOC, M., BILINSKI, S., ETKIN, L. D. (2004). The Balbiani body and germ cell determinants: 150 year later. Curr. Top. Dev. Biol. 2004; 59:1-36.

KLOC, M., MATUSZEWSKI, B. (1977). Extrachromosomal DNA and the origin of oocytes in the telotrophic - meroistic ovary of Creophilus maxillosus (L). (Staphylinidae, Coleoptera-Polyphaga). Roux's Arch. Dev. Biol. 183, 351-368.

KLOC, M., MATUSZEWSKI, B., NURKOWSKA, J. (1995). Ribosomal gene amplification in ooctytes of Creophilus maxillosus (Staphylinidae, ColeopteraPolyphaga)- an insect with telotrophic ovaries. Folia Histochem Cytobiol. 33, 267-276

KLOC, M. AND ZAGRODZINSKA, B. (2001). Chromatin elimination - an oddity or a common mechanism in differentiation and development. Differentiation 68 : 84-91.

KLOC, M., ZEARFOSS, N. R., ETKIN, L. D. (2002). Mechanisms of subcellular mRNA localization. Ce// 108:533-44

KRACZKIEWICZ, Z. (1935).Nouvelles recherches sur l'oogenese et la diminution dans le larves paedogenetiques de Miastor metraloas (Diptera). C. R. Soc. Biol. (Paris) 119: 1201-1205.

KRACZKIEWICZ, Z. (1938). La spermatogenese chez Miastor metraloas (Diptera) C. R. Soc. Biol. (Paris) 127: 1143-1145.

KRACZKIEWICZ, Z., MATUSZEWSKI, B. (1958). Observations on an atypical structure of salivary chromosomes of certain Cecidomyidae. Chromosoma 9: 484-92.

KUNZ, W. AND ECKHARDT, R. A. (1974). The chromosomal distribution of satellite DNA in the germ-line and somatic tissues of the gall midge, Heteropeza pygmaea. Chromosoma 47: 1-19.

MAGNENAT, L., TOBLER, H., MULLER F.(1999). Developmentally regulated telomerase activity is correlated with chromosomal healing during chromatin diminution in Ascaris suum. Mol. Cel/ Biol. 19:3457-3465.

MATUSZEWSKI, B. (1982). Diptera I: Cecidomyiidae. Animal Cytogenetics, vol. 3 p. 1-140, Insecta 3, Ed. John B, Canberra, Australia. Gebruder Borntraeger, 
Berlin Stuttgart.

MATUSZEWSKI, B., CIECHOMSKI, K., KLOC, M (1999). Extrachromosomal rDNA and polarity of pro-oocytes during ovary development in Creophilus maxillosus (Coleoptera, Staphylinidae). Folia Histochem. Cytobiol. 37, 179-190.

MULLER, F. AND TOBLER, H. (2000). Chromatin diminution in the parasitic nematodes ascaris suum and parascaris univalens. Int. J. Parasitol. 30:391399.
PRESCOTT, D. M. (2000). Genome gymnastics: unique modes of DNA evolution and processing in ciliates. Nat Rev Genet. 1:191-198.

WATT, M. R. (1998). Bitter Glory: Poland and Its Fate, 1918-1939. New York. Hippocrene Books.

ZHOU, Y. AND KING, M. L. (2004) Sending RNAs into the future: RNA localization and germ cell fate. IUBMB Life. 56: 19-27.

\section{Related, previously published Int. J. Dev. Biol. articles}

See our recent Special Issue Developmental Biology in Poland edited by Kloc, Maleszewski and Tarkowski at: http://www.ijdb.ehu.es/web/contents.php?vol=52\&issue=2-3

See our Special Issue Mammalian Reproduction \& Development in honor of Anne McLaren and edited by Brigid Hogan at: http://www.ijdb.ehu.es/web/contents. php?vol=45\&issue=3

2006 ISI ${ }^{* *}$ Impact Factor $=3.577^{* *}$
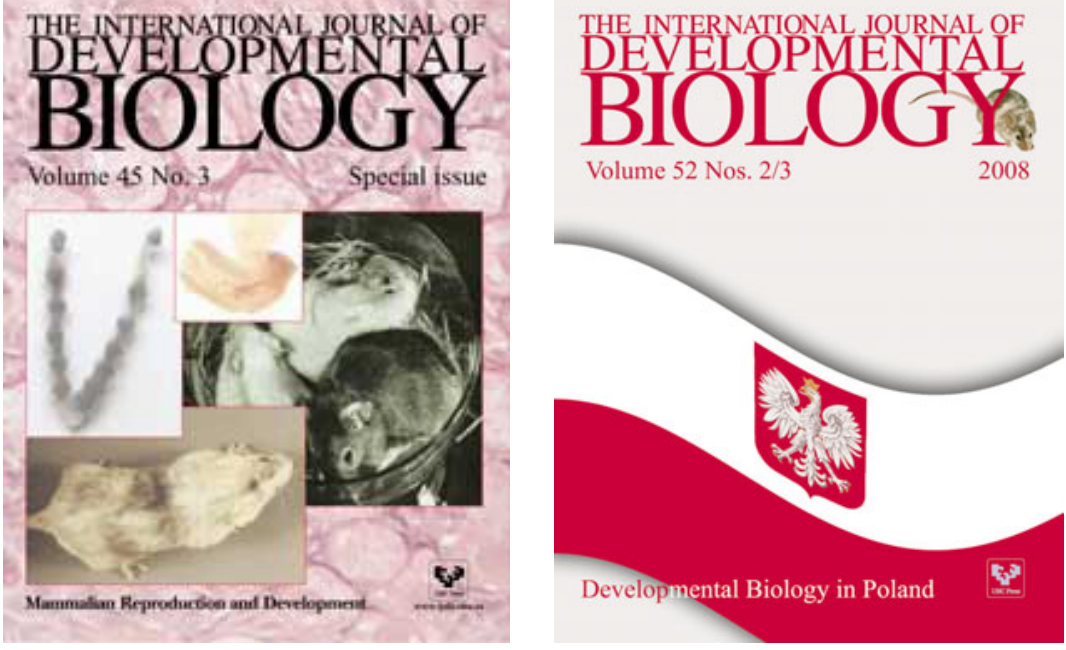